\title{
ALGUNS DADOS REFERENTES AO ESTUDO PARASITOLÓGICO E ANATOMOPATOLÓGICO DE DUAS LINHAGENS DE SCHISTOSOMA MANSONI SAMBON, 1907 *
}

Luiz A. Magalhães *

Francisco G. Alcântara **

José F. Carvalho***

\begin{tabular}{r|r|}
$\operatorname{RSPU}-\mathrm{B} / 240$ \\
\hline
\end{tabular}

MAGALhÃES, L. A. et al. - Alguns dados referentes ao estudo parasitológico e anatomopatológico de duas linhagens de Schistosoma mansoni Sambon, 1907. Rev. Saúde públ., S. Paulo, 9:1-5, 1975.

Resumo: Foi estudada a ação patogênica das linhagens de Schistosoma mansoni dos municípios de Belo Horizonte, $M G$ e de São José dos Campos, $S P$ (Brasil) observando maior capacidade patogênica da linhagem do primeiro, nas condições da experiencia.

Unitermos: Esquistossomose mansônica. Patologia. Linhagens.

\section{INTRODU C A O}

As linhagens de Schistosoma mansoni oriundas de São José dos Campos, SP e de Belo Horizonte, MG (Brasil) são mantidas na natureza por moluscos de espécies diferentes (Biomphalaria tenagophila e $B$. glabrata, respectivamente), assinalando-se resistência a infecção cruzada entre elas (Paraense \& Correa ${ }^{7,8}, 1963$ ). As espécies de moluscos em questão apresentam elevado grau de competição, não sendo encontradas cohabitando na natureza (Magalhães $\left.{ }^{3}, 1966\right)$. Admitimos que estes fatos levariam ao isolamento geográfico das linhagens estudadas, não fosse a migração freqüente, em certas regiões do país, do hospedeiro humano. De qualquer forma acreditamos haver um isolamento parcial entre as duas linhagens o que fa- voreceria o estabelecimento, cada vez maior, de diferenças de comportamento entre elas.

Paraense ${ }^{6}$ (1963) assinalou a existência destas linhagens e Magalhães e Carvalho ${ }^{5}$ (1973), relataram diferenças morfológicas entre vermes adultos destas cepas.

Iniciamos, por este motivo, uma linha de pesquisa na qual procuramos estudar comparativamente os diferentes aspectos apresentados por estas linhagens no que diz respeito à patologia apresentada em camundongos experimentalmente infectados. Neste trabalho, relatamos os resultados obtidos em duas experiências que visaram comparar a patologia provocada pela infecção esquistossomótica.

\footnotetext{
* Trabalho realizado com auxílio do Conselho Nacional de Pesquisas (CNPq)

** Do Instituto de Biologia da UNICAMP - Caixa Postal 1170 - Campinas, SP - Brasil

*** Do Instituto de Ciencias Matemáticas de São Carlos, USP - São Carlos, SP - Brasil
} 
MAGALHÃES, L.A. et al. - Alguns dados referentes ao estudo parasitológico e anatomopatológico de duas linhagens de Schistosoma mansoni Sambon, 1907. Rev. Saúde públ., 9: $1-5,1975$.

\section{MATERIAL E MÉtodos}

\subsection{Primeira experiência}

Foram infectados, por imersão, dois lotes de camundongos pesando aproximadamente de 14 a $16 \mathrm{~g}$, com cercárias de $S$. mansoni.

O primeiro lote, composto de 23 camundongos, foi infectado com $S$. mansoni de Belo Horizonte $(\mathrm{BH}) .0$ segundo lote, composto de 17 camundongos, foi infectado com S. mansoni de São José dos Campos (SJ).

Os camundongos foram sacrificados 60 dias após a infecção sendo contados os esquistossomos extraídos através da perfusão dos vasos mesentéricos e hepáticos (Yolles e col. ${ }^{10}$, 1947; Brener ${ }^{1}, 1962$ ). $\mathrm{Na}$ mesma época foram contados os granulomas hepáticos após liquidificação do fígado segundo técnica descrita por Pellegrino e Brener ${ }^{9}$ (1956) e Brener e col. ${ }^{2}$ (1956).

Os resultados da experiência foram analisados estatisticamente através do teste $\mathrm{U}$ de Mann-Whitney, relativo à hipótese genérica: $\mathrm{H}_{0}=\mathrm{fA}=\mathrm{fB}$ e $\mathrm{H}_{1}=\mathrm{fA} \neq \mathrm{fB}$ em que $f A$ significa "função de densidade da população de onde se obteve a primeira amostra" e fB "função de densidade da população de onde se obteve a segunda amostra". O nível de significância utilizado foi, sempre, $5 \%$.

\subsection{Segunda experiência}

Foram infectados 15 camundongos com cercárias de $S$. mansoni de Belo Horizonte e outros 10 camundongos com cercárias de S. mansoni de São José dos Campos.

Após 60 dias da infecção, foram sacrificados os roedores, contados os esquistossomos do fígado, da veia Porta e dos vasos mesentéricos segundo técnica de Yolles e col. ${ }^{10}$ (1947) e Brener ${ }^{1}$ (1962). Do lóbulo direito do fígado retiramos uma fatia e fixamo-la em formol cálcio para estudo histológico. Foram preparados cortes de $7 \mu$ de espessura, corados pelo $\mathrm{HE}$ e pelo tricrômico de Masson. Os granulomas esquistossomóticos foram contados após medida da área dos cortes por planimetria.

Os fígados foram pesados após terem sido desumidificados em papel de filtro. Este procedimento também foi feito com fígado de animais testemunhas, não identificados.

\section{RESULTADOS}

\subsection{Primeira experiência}

Encontramos, nos 23 camundongos infectados pela linhagem de Belo Horizonte, 271 esquistossomos e o total de 29.482 granulomas hepáticos. Baseados nestes da-

TABELA 1

Número de granulomas obtidos por liquidificação de fígado de camundongos infectados por S. mansoni - Relação granuloma-vermes

\begin{tabular}{c|c|c|c|c}
\hline Linhagens & $\begin{array}{c}\text { Número de } \\
\text { camundongos } \\
\text { infectados }\end{array}$ & $\begin{array}{c}\text { Número de } \\
\text { vermes obtidos } \\
\text { por perfusão }\end{array}$ & $\begin{array}{c}\text { Total de } \\
\text { granulomas } \\
\text { obtidos }\end{array}$ & $\begin{array}{c}\text { Granulomas } \\
\text { por } \\
\text { vermes }\end{array}$ \\
\hline $\mathrm{BH}$ & 23 & 271 & 29.482 & 109 \\
$\mathrm{SJ}$ & 17 & 153 & 11.691 & 76 \\
\hline
\end{tabular}


MAGALHAES, I.A. et al. - Alguns dados referentes ao estudo parasitológico e anatomopatológico de duas linhagens de Schistosoma mansoni Sambon, 1907. Rev. Saúde piibl., 9: $1-5,1975$.

dos verificamos que, em média, para cada esquistossomo de Belo Horizonte foram encontrados 109 granulomas hepáticos.

Nos 17 camundongos infectados com cercárias de São José dos Campos foram contados 153 vermes e 11.691 granulomas hepáticos, obtendo-se a média de 76 granulomas por verme (Tabela 1).

\subsection{Segunda experiência}

Os resultados desta fase do trabalho estão contidos nas Tabelas 2.3 e 4 .

\section{TABEA 2}

Peso do figado * de camundongos infectados por S. mansoni e do grupo controle**

\begin{tabular}{|c|c|c|}
\hline $\begin{array}{c}\text { Linhagem } \\
\text { BH }\end{array}$ & $\begin{array}{c}\text { Linhagem } \\
\text { SJ }\end{array}$ & Controle \\
\hline 2.16 & 3.08 & 1.18 \\
\hline 1,63 & 2,46 & 1,53 \\
\hline 1,27 & 2,84 & $1,3 \tilde{3}$ \\
\hline 2,12 & 1,52 & 1,68 \\
\hline 3.72 & 2,31 & 1,25 \\
\hline 2,18 & 2.37 & 1.46 \\
\hline 2,58 & 2,08 & 1,46 \\
\hline 2,15 & 2,75 & 1,46 \\
\hline 1,84 & 2,60 & 1,11 \\
\hline 2,67 & 1,83 & 1,14 \\
\hline 3,01 & & \\
\hline 2,41 & & \\
\hline 3,77 & & \\
\hline 3,60 & & \\
\hline 2,60 & & \\
\hline 2,89 & & \\
\hline 2,53 & $2,38 *$ & 1,36 \\
\hline
\end{tabular}

em gramas

por ocasiāo do sacrifício dos animais o peso corporal variava entre 25 a $30 \mathrm{~g}$ média do peso dos figados
TA B E L A 3

Número de S. mansoni obtidos por perfusão do sistema porta dos camundongos infectados

\begin{tabular}{c|c}
\hline Linhagem BH & Linhagem SJ \\
\hline 8 & 8 \\
5 & 27 \\
13 & 4 \\
10 & 12 \\
31 & 15 \\
21 & 10 \\
10 & 3 \\
8 & 12 \\
14 & 13 \\
10 & 2 \\
17 & \\
16 & \\
5 & \\
23 & \\
3 & \\
\hline 12,9 & $10,6 *$ \\
\hline
\end{tabular}

média dos vermes por perfusão

TABEA 4

Número de granulomas por $\mathrm{mm}^{2}$ de cortes histológicos de $7 \mu$ de espessura de fígados de camundongos infectados

\begin{tabular}{c|c}
\hline Linhagem BH & Linhagem SJ \\
\hline \hline 1.71 & 0,55 \\
1,80 & 1.01 \\
1.87 & 0,33 \\
1,74 & 0.44 \\
1.94 & 0.43 \\
2,14 & 0.34 \\
1,10 & 0.29 \\
0,87 & 0.75 \\
1.53 & 0.79 \\
1.50 & 0,44 \\
1,65 & \\
1.60 & \\
0.82 & \\
3.30 & \\
0,90 & \\
$1,63 *$ & \\
\hline
\end{tabular}

média de granulomas por $\mathrm{mm}^{2}$ 
MAGALHÃES, L.A. et al. - Alguns dados referentes ao estudo parasitológico e anatomopatológico de duas linhagens de Schistosoma mansoni Sambon, 1907. Rev. Saúde públ., 9: $1-5,1975$.

Submetemos os resultados das duas experièncias a cálculos estatísticos utilizandose o nível de significância de $5 \%$.

\section{DISCUSSAO}

Tendo em vista os resultados contidos na Tabela 1 e levando-se em consideração que em trabalho anterior (Magalhães $\mathrm{e}$ Carvalho ${ }^{5}$, 1969), não havíamos encontrado diferença significativa na proporção macho-fêmea nas linhagens estudadas e que na gênese do granuloma esquistossomótico incrimina-se, principalmente, o ovo do verme, poderíamos concluir que as fêmeas da linhagem SJ ovipuseram, em nossa experiência, menos que as fêmeas da linhagem BH. Outra hipótese é a de que os ovos provenientes dos helmintos das duas linhagens apresentem diferente distribuição no organismo do camundongo.

0 número de granulomas por área de corte foi correlacionado com o número de esquistossomas encontrados nos roedores, assim como, com o peso médio dos fígados dos camundongos infectados (Tabelas 2, 3 e 4).

Com relação aos dados contidos na Tabela 2 , concluimos que o peso dos fígados dos camundongos infectados, é estocasticamente maior do que o peso dos fígados de camundongos testemunhas.

Não houve, contudo, diferença significativa entre a média do peso dos fígados dos camundongos infectados pela linhagem SJ com relação aos infectados pela linhagem $\mathrm{BH}$.

Analisando os resultados fornecidos pela Tabela 4, concluimos que o número de granulomas por $\mathrm{mm}^{2}$, por verme, da linhagem $\mathrm{BH}$ é estocasticamente superior ao número de granulomas da linhagem SJ.

Finalmente, aceitamos a hipótese de que - número de esquistossomos encontrados por perfusão dos camundongos da linhagem $\mathrm{BH}$ foi igual ao da linhagem SJ (Tabela 3 ).

\section{CONCLUSAO}

Nas experiências realizadas ficou demonstrado que o número de granulomas por verme da linhagem de Belo Horizonte (BH) foi superior ao observado na linhagem de São José dos Campos (SJ). Verificamos também um aumento significativo do peso do figado nos camundongos infectados pelas duas linhagens estudadas.

RSPU-B $/ 240$

MAGALHÃES, L. A. et al. - [Some data regarding the parasitological and anatomopathological studies of two strains of Schistosoma mansoni Sambon, 1907.] Rev. Saúde públ., S. Paulo, 9:1-5, 1975

SUMMARY: An experiment was carried out in order to determine differences in the pathology of two $\mathbf{S}$. mansoni strains, one from the state of Minas Gerais (Belo Horizonte) and the other from the State of S. Paulo ( $S$. José dos Campos), Brazil. Mice were infected with both strains under experimental conditions and the comparative study of these animals showed significant differences as regards pathology of the tissue lesions. The Belo Horizonte strain showed a higher level of pathogenicity when compared to the $\mathrm{S}$. José dos Campos one.

UnITERMS: Schistosoma mansoni. Pathology. Strains. 
MAGALHAES, L.A. et al. - Alguns dados referentes ao estudo parasitológico e anatomopatológico de duas linhagens de Schistosomc mansoni Sambon, 1907. Rev. Saúde pübl., 9: 1-5, 1975 .

\section{REFERENCIAS BIBLIOGRAFICAS}

1. BRENER, Z. - Contribuição ao estudo da terapêtica experimental da esquistossomose mansônica. Belo Horizonte, 1962. [Tese para cátedra]

2. BRENER, $\boldsymbol{Z}$. et al. - Terapêutica experimental da esquistossomose mansoni Aplicação do método de isolamento de granulomas do figado de camundongos. Rev. bras. Malar., 8:583-7, 1956.

3. MAGALHAES, L.A. - Estudo de uma população de Biomphalaria glabrata (Say, 1818), recentemente introduzida no estado da Guanabara. Folia clin. biol., S. Paulo, 35:102-20, 1966.

4. MAGALHÃES, L.A. \& CARVALHO, J.F. - Verificação do número de machos e fêmeas de Schistosoma mansoni capturados em camundongos infectados por duas cepas do helminto. Rev. Soc. bras. Med. trop., 3:253-4, 1969.

5. MAGALHAES, L.A. \& CARVALHO, J.F. - Estudo morfológico do Schistosoma mansoni pertencentes as linhagens de Belo Horizonte (MG) e de São José dos Campos (SP). Rev. Saúde públ, S. Paulo, 7:289-94, 1973.
6. PARAENSE, W.L. \& CORREA, L.R. Variation in susceptibility of Australorbis glabratus to a strain of Schistosoma mansoni. Rev. Inst. Med. trop. S. Paulo, 5:15-22, 1963.

7. PARAENSE, W.L. \& CORREA, L.R. Susceptibility of Australorbis tenagophilus to infection with Schistosoma mansoni. Rev. Inst. Med. trop. S. Paulo, 5:23-9, 1963.

8. PARANENSE, W.L. \& CORREA, L.R. - Sobre a ocorrência de duas raças biológicas do Schistosoma mansoni no Brasil. Cien. Cult., 15:245-6, 1963.

9. PELlEGRINO, J. \& BRENER, Z. - Method for isolating schistosome granulomas from mouse liver. J. Parasit., 42:564, 1956 .

10. YOLLES, T.K.; MOORE, D.V.; DE GIUSTI, D.L.; RIPSON, C.A. \& MELENEY, H.E. - A technique for the perfusion of laboratory animals for the recovery of schistosomes. J. $P a$ rasit., 33:419-26, 1947.

Recebido para publicaçāo em 09-10-74 Aprovado para publicacão em 13-01-75 